\title{
Die rivier van die lewe in Esegiël 47: Motief, mite en metafoor
}

\author{
Louis C Bezuidenhout \\ Departement Bybelkunde \\ Universiteit van Pretoria
}

\begin{abstract}
The river of life in Eseliel 47:1-12: Motif, myth and metaphor

This aricle tries to establish the nawre and value of the myls and metophors imbedded in the description of the tiver of Wf in Lsektet $471-12$. The Bibltcal context as well as the wider mphologicat comext is taken tho acconmt. $n$ commanicates Gads saving acts and the opitival recreation of the people in

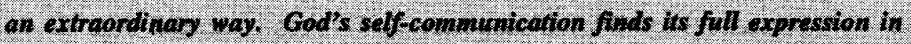
an inwardy rencwed comanniy. The artide inchutes a reflection on the moture and value of the myth and the metaphor in theology.
\end{abstract}

\section{INLEIDING}

Esegiël het sy geloof anders beleef as die moderne gelowige - anders veral as die rasionele, nugtere lidmaat van 'n Afrikaanse kerk in die Hervormde tradisie. Esegiël se konsepte is gekleed in visoenêre, verbeeldingryke voorstellings. Sy ervarings is dikwels ekstaties. Die inhoud van sy profesieë getuig van intense spirituele ervarings. Die teks het 'n visualiteit wat sowel esoteries as aards kan wees. Dit is 'n teks met vitaliteit. Die teks bied skuiling aan ou mites en tradisies wat in onguns verval het in die religie. Tog klink dit as 'n ondertoon steeds saam met "kontemporêre" aspekte. Die metafore is pregnant. Dit word saamgestel uit die palet van basiese menslike belewenisse - verhewe sowel as platvloers, geestelik sowel as sensueel. Die metafore is nie geslote nie - dit is polivalent en nooi die leser uit om mee te werk aan die betekenisgewing van die teks.

Ons leef in 'n tyd waarin die Nederduitsch Hervormde Kerk sensitief is vir die gevare van gevoelsmatige en ekstatiese geloofsbelewing asook vir die aantasting van 
die verhewenheid van godsdiens. Die kerk oorweeg dit om nuwe, eietydse belydenisskrifte te ontwikkel waarin die geloof van die kerk op 'n moderne, ondubbelsinnige en suiwere manier geformuleer word. Wanneer dit die doel is van 'n nuwe belydenis, wonder ' $n$ mens dadelik of daar ruimte is vir die antieke mite en metafoor. Die antieke mite verteenwoordig 'n verwysingsraamwerk wat radikaal verskil van die moderne en die metafoor is noodwendig veelduidend. In hierdie artikel word die dinamika van die mite en die metafoor in Esegiël 47:1-12 bestudeer ten einde die waarde daarvan vir religieuse literatuur te bepaal.

Die rivier van die lewe in Esegiël 47 word as voorbeeld gekies omdat verskillende verwysingsraamwerke daarin ingebed is. Dit toon ' $n$ mitologiese en metaforiese gelaagdheid. Dit bevat antieke Kanaänitiese en Babiloniese motiewe wat op 'n bepaalde manier resoneer in die Christelike geloof. Dit handel oor die oorsprong en die einddoel. In Esegiël 47:1-12 word "kontemporêre" perspektiewe ook verreken. Nuwe relasies en perspektiewe ontstaan wanneer ou en nuwe verwysingsraamwerke in jukstaposisie geplaas word.

In die artikel word hierdie aspekte ontgin en aangedui dat elkeen 'n waardevolle bydrae maak tot die "betekenis" van die teks. Die eliminering van sulke aspekte in religieuse literatuur sal lei tot 'n verarming van die betekenis van die teks. Dit is die hoop van die skrywer dat daar 'n herwaardering sal wees van die waarde van die mite en die metafoor in religieuse literatuur. Hierdie resultate mag dalk implikaşies hê vir die funksie van die mite en metafoor in toekomstige religieuse literatuur.

\section{DIE RIVIER VAN DIE LEWE BINNE RELEVANTE KON- TEKSTE}

In die volgende paragrawe word die motief van die Rivier van die Lewe binne verskillende kontekste bestudeer om sodoende verskillende aspekte van die teks na vore te bring.

\subsection{Die rivier van die lewe in 'n wyer mitologiese konteks}

Die gegote waterbak (gegote see) by die tempel (vgl 1 Konings 7:23-26) kan aan ons 'n sleutel voorsien vir die interpretasie van die rivier van die lewe in Esegiël. In sy artikel toon Zwickel dat Esegiël verwys na werklike elemente van die tempel in sy visioene alhoewel dit geidealiseer en aangepas is. Volgens hom is die religieus- 
historiese agtergrond van die gegote waterbak ook gereflekteer in Esegiël se visioen van die rivier van die lewe (Zwickel 1995:148-154).

Die gegote waterbak was 'n groot bak van 5 meter in deursnee en 2.5 meter hoog. Dit het op 12 brons osse gestaan. Volgens 2 Kronieke 4:6 het die priesters die water in die bak gebruik vir reiniging. Dit is moontlik dat die bak gebruik kon word as waterhouer, maar sy grootte het dit onwaarskynlik gemaak dat dit as 'n voorwerp kon dien om in te was.

In 1956 het W F Albright aandag gevestig op die parallelle tussen die gegote waterbak by die tempel van Salomo en soortgelyke waterhouers by Mesopotamiese tempels. Vandag is ons bewus van talle voorbeelde van voorwerpe soortgelyk aan die gegote waterbak in ander kulture van die Ou Nabye Ooste (vir 'n lys van publikasies kan Zwickel 1995:150-151 geraadpleeg word). In Mesopotamië het hierdie voorwerpe die naam apsû wat verwys na die soet onderaardse water. Dit is moontlik dat die waterbak by die tempel oorspronklik hierop gedui het.

Die feit dat die bak by die tempel op beelde van beeste staan, kan 'n polemiese funksie hê. Othmar Keel is van mening dat die beelde van beeste in Kanaän vegkrag voorstel (vgl Keel 1992:134, 147, 164, 192). Hierdie struktuur by die tempel kan suggereer dat JHWH met krag die god Apsa verslaan het. Of hierdie interpretasie vir alle tye geldig is, is twyfelagtig. Het Agas miskien die oorspronklike betekenis van die waterbak herstel toe hy dit verwyder het van die staander gevorm deur die twaalf beeste?

Bulle kan ook 'n teken van vrugbaarheid wees. Die bulle onder die waterbak kan die lewegewende funksie van die "see" uitbeeld. Dit is duidelik dat die teenwoordigheid van water by die tempel 'n besliste religieus-historiese basis het.

Daar is ' $\mathrm{n}$ interessante gedeelte in die Akkadiese gebede met opgeligte hande (vgl Ebeling 1953:14, 16) waar die waterbak geassosieer word met Apsû en die wierookaltaar met Anu. Dit is logies dat die water verwys na die god van die onderaardse see (Apsû) en die rook na die god van die hemel (Anu). Is hierdie assosiasie relevant ten opsigte van die altaar en waterbak voor die tempel in Jerusalem?

In die Gilgamesj-epos (tablet XI reëls 266-280) kry ons 'n verwysing na die plant van die lewe wat in die Apsû groei. Hierdie plant kan 'n mens se jeug herstel. Die verband tussen Apsû en die plant van die lewe kan relevant wees vir ons verstaan van die rivier van die lewe in Esegiël 47:1-12. Volgens Esegiël 47:12 sal die bome wat groei, se vrugte nie opraak nie, en die blare sal genesende krag hê. 
In die Babiloniese skeppingsverhaal is daar 'n verwantskap tussen godin, berg en rivier. Nadat hy Tiamat doodgemaak het, het Marduk 'n berg oor haar kop gebou en haar oë deurboor om die bronne van die Tigris en Eufraat te vorm. Hy het soortgelyke heuwels oor haar borste gevorm wat hy deurboor het om die riviere van die oostelike berge te vorm wat in die Tigris invloei (Jacobsen 1976:179).

In Esegiël 47:9 word die dualisvorm van "rivier" gebruik (נָחחָלִיִים), maar die werkwoord is in die enkelvoud. Kommentatore verander gewoonlik die woord na die

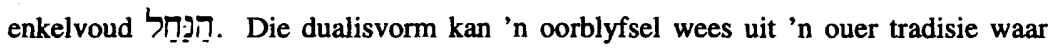
daar van twee strome sprake is wat ontspring in die oë of borste van die godin (vgl Sagaria 14:8).

Die samevloeiing van die vars water en die sout water herinner 'n mens aan die vereniging van Apsû en Tiamat, die voorvaders van die gode.

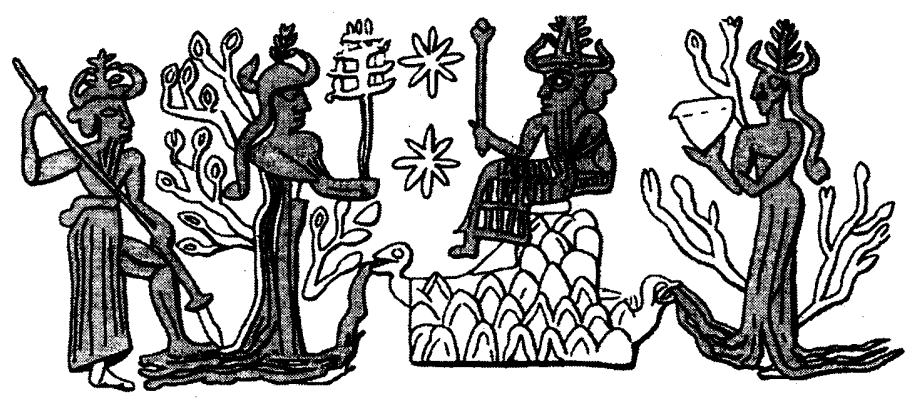

Antieke ikonografie bied aan ons waardevolle vergelykbare uitbeeldings. Op 'n silinderseël (2350-2150 v C.) uit Mari (vgl Keel 1992:47) sien ons die koning van die gode wat sit op 'n berg. Onder die koning vloei twee riviere in teenoorgestelde rigtings. Twee godinne verrys uit die strome. Hulle is godinne van plantegroei. Die een hou ' $n$ boom in haar hand en die ander ' $n$ houer. Dit is waarskynlik van Babiloniese oorsprong. Die god is Anu en die figuur aan die linkerkant wat met die rivier veg, is Marduk. Dit kan ook van Kanaänitiese oorsprong wees. Dan is die koning El en die persoon met die spies Baäl (Keel 1992:48). Hier word die dubbele karakter van water gedemonstreer. Aan die een kant bring water lewe, aan die ander kant chaos en dood. 


\subsection{Die rivier van die lewe binne 'n Bybelse konteks}

Die metafoor van die rivier word in antieke literatuur dikwels gekombineer met die metafoor van die berg van die paradys. Die metafoor van die berg kom voor in Jesaja 2:2; Psalm 48:3 en Sagaria 14:10. In al hierdie tekste het die metafoor van die berg betrekking op die berg Sion. In Sagaria 14 word die metafoor van die berg gekombineer met die metafoor van die rivier. Ook die rivier word hier direk aan Sion verbind. Dit sal sinvol wees om 'n deeglike studie te maak van die metafoor van die berg van die paradys en die verband tussen hierdie metafoor en die metafoor van die rivier van die lewe. Hierdie artikel handel egter net oor die metafoor van die rivier en die metafoor van die berg sal nie binne die Bybelse konteks verder bespreek word nie.

Die metafoor van die rivier word gevind in Genesis 2:10-14; Jesaja 33:21; Esegiël 47:1-12; Joël 3:18; Sagaria 13:1; 14:8; Psalm 36:9-10; 46:5 en Openbaring 22:1-2. In Genesis 2 word die metafoor gebruik om na die oorspronklike paradys te verwys, in Openbaring 22 verwys dit na die verlossing in die eindtyd as 'n terugkeer na die paradys. In Openbaring 22 word die rivier verbind aan die Nuwe Jerusalem, die sentrum van die nuwe paradys. Die paradysmotief kom ook in 'n mindere of meerdere mate voor in Jesaja 33, Joël 3, Esegiël 47 en Sagaria 14. In al die gevalle word dit verbind aan Sion.

Vir Zwickel (1995:144-148) is dit belangrik om die datering van hierdie tekste vas te stel sodat ' $n$ mens kan weet of dit as bronne vir die gesig van Esegiël kan dien. 'n Teks wat ouer is as Esegiël 47:1-12, kan dus moontlik 'n bron wees vir die gesig in Esegiël 47:1-12. Die uitbeelding van die paradys in Genesis 2 is moeilik om te dateer. Die verskillende teorieë oor die datering van hierdie gedeelte kan in Zwickel (1995:1 45) nagegaan word. 'n Mens kan met Zwickel saamstem dat Gen 2:10-14 gesien moet word as deel van die Nachwirkungsgeschichte van Esegiël 47:1-12 eerder as die vorgegebene Tradition.

Ten opsigte van die vier riviere wat in Genesis 2 genoem word, is die naam Eufraat bekend. Die Hiddekel is die Tigris. Die Pison en Gihon kan nie geïdentifiseer word as twee van die vername riviere nie (Westermann 1976:298). Die woord

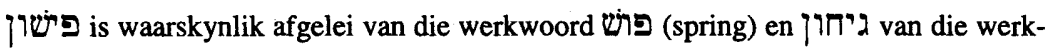
woord ำ (uitbars) (Westermann 1976:296). Hierdie name beskrywe waarskynlik die tipiese eienskappe van ' $n$ fontein. In Jerusalem is die fontein inderdaad Gihon genoem. 
Dit is interessant dat die geboorte van die see beskryf word as "uitbreek" ('ग) in Job 38:8. Daar word die ontstaan van die see geskets as die geboorte van 'n

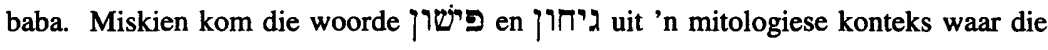
geboorte van die see en riviere beskryf word.

Indien die boek van Esegiël aan die skrywer van Genesis 2:10-14 bekend was, moes hy geweet het dat die leser waarskynlik die assosiasie tussen die rivier in die paradys met die naam Gihon en die fontein in Jerusalem sou maak. Daar sou in die lesersresepsie 'n verband bestaan tussen Gihon in Genesis 2:10-14 en die rivier in Esegiël 47 (vgl Zwickel 1995:146). Tog dui die lokalisering van Gihon in die land Kus daarop dat dit geografies nie met die Gihonfontein in Jerusalem verbind kan word nie. Volgens Hans Wildberger is Jesaja 33:17-24 'n latere invoeging in die teks. Die stelling dat Jerusalem 'n bron van riviere sal wees, is nog 'n later toevoeging tot hierdie laat teks (Wildberger 1982:1309-1323). Hierdie teks, sowel as Sagaria, Joël en Openbaring, staan in die Nachwirkungsgeschichte van Esegiël 47:1-12 (vgl Zwickel 1995:146-147).

Die genoemde tekste uit die psalms is moeilik om te dateer. Psalm 36 is waarskynlik redelik laat geskryf. Afhanklikheid van Esegiël 47 kan nie bewys word nie, maar dieselfde tradisie van die rivier is opgeneem (vgl Kraus 1978:433-435). Die datering van Psalm 46 is onseker - dit is tussen die laat voor-eksiliese tyd en die naeksiliese tyd (vgl Zwickel 1995;146-147 vir 'n lys van verwysing). In Psalm 46:5 verwys die digter na die fontein Gihon: "'n Rivier (נהר) maak die Godstad bly, die heiligste van die woninge van die Allerhoogste." Hierdie voorstelling van die rivier is reeds gekleur deur mitologiese beeldspraak. Dit mak die stad bly in die sin dat dit vrugbaarheid en groei bring (vgl Psalm 65:10). Ten opsigte van Psalm 65 toon Silvia Schroer aan dat daar ooreenkomste is met die Tweede Jesaja en stel 'n laat datering voor (Schroer 1990:285-301).

Die fontein van Gihon is nie die oorsprong van die mitologiese beeldspraak nie, dit is gekleur deur antieke mitologiese beeldspraak. Psalm 46 kan nie beskou word as 'n bron vir die beelde in Esegiël 47 nie, maar dit openbaar dieselfde invloede.

Nou moet daar bepaal word wat die verband is tussen die Gihon in die paradys, die Gihonfontein in Jerusalem en die fontein by die tempel. In Jesaja 8:6vv vind ons 'n voorstelling wat die water van Gihon as metafoor vir die Here gebruik: "Omdat hierdie volk die waters van Siloag verag wat saggies vloei, en bang geword het vir 
Resin en die seun van Remália, kyk, daarom sal die Here oor hulle laat opkom die sterk en magtige waters van die Eufraat ..."

Die "waters van Siloag" is die stelsel van kanale wat die water van Gihon lei langs die oostelike helling van die heuwel. Dit verwys na die Here wat deur die volk verlaat is, maar wat die magtige water van die Eufraat beheer. Hierdie teks was waarskynlik bekend aan Esegiël en dit kon die visioen in Esegiël 47:1-12 beïnvloed. Daar mag ooreenkomste wees tussen die Gihonfontein en die rivier in Esegiël 47:1-12, maar die ooreenkomste lê in die karakter van die bronne en nie in hulle ligging nie. Hulle is beslis nie identies nie.

Die fontein wat op die tempelberg ontspring, kan vanuit 'n geografiese oogpunt beswaarlik verwys na 'n bestaande fontein. Tog word so ' $n$ fontein vermeld word deur Tacitus sowel as in die Brief van Aristeas (vgl Zimmerli 1983:510). Die motief van die fontein op die tempelberg bestaan dus wel in die literatuur, alhoewel dit nie 'n historiese werklikheid is nie.

Volgens Esegiël 47:8 vloei die rivier in die see aan die oostekant en maak die water gesond. In vers 8 behoort die woorde wימה המוצאים warskynlik verander

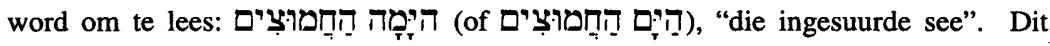
word geïnterpreteer as Soutsee. Hier word natuurlik na die Dooiesee verwys. In Genesis 19 word hierdie gebied geassosieer met die straf van God en moontlik ook die vernietiging van lewe op aarde soos in die geval van die sondvloed. In Genesis 19:31 word gesê dat daar geen man meer op die aarde was nie. Hierdie woorde mag teruggaan op 'n ou tradisie wat die vernietiging van Sodom en Gomorra as 'n totale vernietiging gesien het (vgl Loader 1990:45). In Esegiël 47:8 mag die Soutsee nog iets van die straf van God en miskien ook totale vernietiging suggereer. Die nuwe skepping verander vernietiging in nuwe lewe.

In Esegiël 16:44-58 word Jerusalem beskryf as die suster van Sodom. Hier is ' $n$ interessante vergelyking tussen Jerusalem en Sodom. Jerusalem se skande is groter as Sodom s'n, tog sal Jerusalem herstel word en instrumenteel wees in die herstel van Sodom. Dit sluit aan by die beeld van die stroom uit die tempel wat die Soutsee genees.

God se ingryping in die wêreld word telkens in die Bybel verstaan as 'n reiniging/genesing en ' $n$ herskepping. Dit is ook die perspektief in die Nuwe Testament. Die "bloed van Jesus" reinig, genees en herskep soos die rivier van die lewe in Esegiël 47. In die harte van mense vind die wonder plaas wat geantisipeer is in die 
voorstelling van die rivier van die lewe wat die Dooiesee transformeer. Miskien word die beeld van die groot hoeveelheid vis in die Dooiesee oorgedra in verhale van wonderlike visvangste in die Nuwe Testament.

Daar weerklink iets van die rivier van die lewe in die woorde van Jesus:

... maar wie van die water gedrink het wat Ek hom sal gee, sal in alle ewigheid nooit dors kry nie. Nee, die water wat Ek hom sal gee, sal in hom 'n fontein wees met water wat opborrel en vir hom die ewige lewe gee (Joh 4:14).

Wie my liggaam eet en my bloed drink, het die ewige lewe, en Ek sal hom op die laaste dag uit die dood laat opstaan (Joh 6:54).

Op die laaste dag, die groot dag van die huttefees, het Jesus daar gestaan en uitgeroep: "As iemand dors het, laat hy na My toe kom en drink! Met die een wat in My glo, is dit soos die Skrif sê: Strome lewende water sal uit sy binneste vloei" (Joh 7:37-38).

\subsection{Die rivier van die lewe in in die konteks van Esegiël}

Die boek Esegiël kan in drie dele verdeel word:

- Oordeelsaankondiging oor Juda en Jerusalem,

- 25- 32 Oordeelsaankondiging oor die vreemde volke,

- Heilsaankondiging.

Die tempel speel ' $n$ belangrike rol in die heilsaankondiging. Voor die ballingskap plaasgevind het, was die tempel die religieuse sentrum van Israel. Die vernietiging van die tempel het 'n teologiese probleem veroorsaak. Is God magteloos teen die vreemde magte? Is dit die einde van Israel se godsdiens? Esegiël se visioen van die nuwe tempel is ' $n$ aanduiding dat ' $n$ nuwe era op die punt is om aan te breek. Esegiël se visioen van die tempel reflekteer sy herinneringe aan die voor-eksiliese tempel, maar die afmetings is geïdealiseer.

In hoofstukke 40-42 word die nuwe tempel aan Esegiël geopenbaar. Die Here het ' $n$ intrek in die heiligdom geneem en gee instruksies aan die amptenare (43-46). In 47 en 48 lees ons van die rivier wat van die tempel uitvloei sowel as van die verdeling van die land. 
Esegiël 47:1-12 is geskryf in die vorm van 'n gids-toneel. Esegiël word gelei om te sien watter heilsame uitwerking God se intrek in die tempel vir die land het. God se teenwoordigheid bring nuwe lewe vir die land. Dit word uitgebeeld deur middel van ' $n$ rivier wat uit die tempel vloei.

Die teks wat ons het, bevat heelwat redaksionele invoegings. Volgens Zimmerli vorm verse 1-8 die oorspronklike eenheid. Dit is aangevul deur vier afsonderlike gedeeltes. Vers 9 brei uit oor die lewegewende water; vers 10 beskryf die voordeel wat die water vir die vissermanne inhou, vers 11 bevestig dat die moerasse met hulle waardevolle sout nie ook tot niet sal gaan nie en vers 12 handel oor die nut van die vrugte en blare van die bome (Zimmerli 1983:513-514). Dit lyk nie asof latere redaksionele arbeid die intensie van die gedeelte verander het nie. Vir besonderhede kan die kommentare van Eichrodt (1970) en Zimmerli geraadpleeg word (1983).

Zimmerli is reg as hy sê dat 'n mens Esegiël 47:1-12 nie kan verstaan as jy nie die elemente van die tradisies verstaan wat die basis vorm van die voorstellings in die teks nie (Zimmerli 1969:1191). Tradisies vervul telkens 'n metaforiese funksie in hierdie gedeelte. Die betekenis daarvan word in die volgende paragrawe ontgin:

Die water stroom uit die plek van God se teenwoordigheid. Dit ontspring waar die amptelike verteenwoordiger van die tempel sou staan. Die water is ' $n$ boodskapper van verlossing wat deur die Here van die tempel gestuur is. Die nederige verskyningsvorm van die fontein doen nie afbreuk aan die wonderkarakter van die gebeurtenis nie. God het nie die volk in die steek gelaat nie. Die religieuse sentrum gaan weer herstel word. Die rivier wat uit die tempel vloei, vervul die rol van 'n koppelvlak tussen die tempel en die land, tussen God en die volk. Die ooreenkoms tussen hierdie stroom en die fontein van Gihon beklemtoon die tradisie van Sion wat in 'n nuwe vorm wedergebore gaan word.

Die gegote waterbak het waarskynlik aan die suidekant van die altaar gestaan. Die water in Esegiël se visioen vloei waar die waterbak sou gestaan het. Dit vestig die aandag op die parallelle tussen hierdie rivier en die mitologiese agtergrond van die gegote waterbak. Teenoor die statiese simboliek van die gegote see, is hierdie beeld dinamies. Alhoewel die oorspronklike mite van Apsu opgeroep word, verander hierdie visioen die betekenis. Soos in die mite, het ons weer 'n skepping uit die chaos, maar dit fokus nie meer op die krag van die natuur nie. Dit fokus op die wonderbare ingryping van God. 
Esegiël word aan die buitekant om gebring na die oostelike poort. Volgens 44:1-3 is dit gesluit. Slegs die Here is toegelaat om daardie poort te gebruik. Die motief van die geslote poort het gelei tot interessante wyses van uitleg. Sommige Christelike uitleggers het in 44:1-3 'n profesie gesien van die Maagd Maria (vgl Halperin 1993:211; Neuss 1912 - vgl die Indeks: "Maria, Unversehrte Jungfraulichkeit"). Sommige uitleggers (bv Halperin 1993) wat 'n psigo-analitiese benadering tot die teks volg, vind 'n seksuele motief in hierdie beeld. Jerusalem het gemeenskap gehad met verbygangers (16:25): "By elke kruispad het jy vir jou 'n hoogte ingerig en van jou skoonheid iets afskuwelik gemaak. Jy het jou bene/geslagsorgaan oopge-

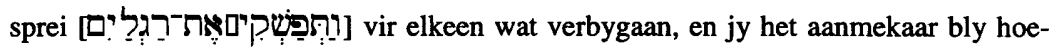
reer." Die ideale tempel se poort sal alleen vir die Here oopgemaak word (44:1-3), en vir die "vors" (vgl Halperin 1993:211): “... Hierdie poort moet toe bly, dit moet nie oopgemaak word nie en niemand mag daardeur gaan nie, want Ek, die Here, die God van Israel, het daardeur gekom; die poort moet toe bly ..."

Die huweliksmetafoor kom in hoofstukke 16 en 23 voor. Dit is duidelik dat Esegiël in sy gebruik van hierdie metafoor steun op ander profete soos Jeremia en Hosea. Tog is Esegiël se hantering van hierdie metafoor in sekere opsigte uniek (vgl Gambush 1992:61).

In hoofstuk 16 word Jerusalem voorgestel as 'n dogtertjie wat gebore is uit Kanaänitiese en Hetitiese ouers. Die Here rę haar en trou uiteindelik met haar. Haar skoonheid is aan die Here te danke. Sy is ontrou aan die Here en pleeg owerspel. Haar naaktheid aan die begin en einde simboliseer haar verdorwenheid. Die Here beklee haar met waardigheid. Alhoewel sy swaar gestraf sal word, sal die Here uiteindelik die verbond met haar vernuwe en haar reinig.

In hoofstuk 23 word Jerusalem en Samaria voorgestel as ontugtige susters (vgl Gambush 1992:63). Die tempel word 'n plek van prostitusie. Jerusalem laat toe dat mans, aan wie sy toegang moes weier, binnekom. Jerusalem sal swaar gestraf word vir haar sonde. Uiteindelik sal sy die gesag van die Here aanvaar. Jerusalem se optrede word dus vergelyk met die seksuele verontreiniging van 'n vrou en haar lot word vergelyk met die gevolge van die woede van 'n verontregte eggenoot. Die metafoor van die ontroue vrou word met byna pornografiese detail beskrywe (Gambush 1992: 124). In hierdie hoofstukke beklemtoon Esegiël die onreinheid van Jerusalem as kultiese sentrum en vergelyk dit met die onreinheid van die vroulike liggaam. 
Tot in watter mate is die metafoor van 'n vrou wat ons in die vorige hoofstukke kry, oorgedra op die nuwe Jerusalem? Daar is 'n doelbewuste poging om die personifikasie van die nuwe stad te vermy. Esegiël wil waarskynlik met hierdie "onpersoonlike" uitbeelding enige assosiasie van seksuele onreinheid ten opsigte van die nuwe Jerusalem vermy. Alhoewel Esegiël 'n personifikasie nie aanmoedig nie, is dit moeilik om dit te voorkom in die lesersresepsie. Dit is asof die metafoor steeds op die agtergrond funksioneer. In Openbaring en 4 Esra is daar weer 'n sterk neiging om die nuwe Jerusalem as God se bruid voor te stel. Die water wat uit die tempel vloei, het 'n reinigende effek. Dit is die teenbeeld van die onrein bloed wat in die verlede gevloei het (vgl Gambush 1992: 154). Die begrip "fontein" word dikwels geassosieer met vroulike seksuele organe en funksies (vgl Levitikus 12:7; 20:18; Spreuke 5:15-20; Hooglied 4:12-15).

Daar is 'n moontlikheid dat die rivier wat uit die tempel vloei, gesien kan word as 'n metafoor vir die geboorte van 'n baba. Op hierdie manier word die oorspronklike mite in herinnering geroep. Vir Esegiël beteken dit 'n nuwe begin, 'n skepping uit chaos. Israel het meer as 'n kosmetiese verandering nodig - hulle het 'n radikale nuwe begin nodig. Hulle ontnugtering in hulle tradisionele waardes en geloof het dit onmoontlik gemaak vir hierdie waardes en geloof om hulle geestelike lewe te laat herlewe. Hulle het 'n ingryping van die Skepper-God nodig.

Die tweede wonder is die feit dat die rivier in volume toeneem. In die Bybel het God se wonders dikwels 'n nederige begin. Dị historiese oorsprong van Israel self was nie so heroïes soos dit in sommige gedeeltes van die Bybel uitgebeeld word nie. Uit 'n godsdiens-historiese perspektief het die godsdiens van Israel 'n nederige oorsprong gehad. In vergelyking met ander volke was Israel altyd 'n klein en onbelangrike volk. Selfs hulle God word vergelyk met die fontein Gihon (Jes 8:6v). Die vermeerdering van die volume is 'n eienskap van die skepping wat geseën is deur God. In die begin het God die visse, voëls en mense geseën (Gen 1:20-31). Soos die gevolge van God se seën toeneem, raak God se dienaar al meer bewus van sy eie geringheid en beperktheid. Soos in die geval van water, impliseer die seën van God voordele sowel as opofferings. Dit oorskry die persoon se vermoë om dit te behecr. Daar is ' $n$ stadium wanneer die siener nie meer deur die water kan loop nie.

Die derde wonder is die feit dat hierdie rivier lewe bring soos die riviere van die paradys. Die rivier oorwin die woestyn en die see van die dood. Bome van die lewe groei van hierdie heilige water. Die aspek van vrugbaarheid word op die voor- 
grond geskuif. Dit bring ons terug by die motief van geboorte. Die water het genesende krag (רפה). Dit kan ook geïnterpreteer word as suiwering. Genesing sowel as suiwering is nodig om die paradys te herskep. Dit is die teenpool van die beeld van die vrou Jerusalem wat haarself ontreinig het (16:1-43; 24:1-14).

Esegiël verkondig nie net die rivier van die lewe nie, sy verkondiging word die rivier van die lewe. Dit bring nuwe lewe onder mense wat geestelik gesterf het (vgl Eseg 37:1-14). In Esegiël 37 het die "gees" hierdie lewegewende funksie. Dit is interessant dat die water en gees ook in die Johannesevangelie gekoppel word aan die nuwe lewe. $\mathrm{Na}$ die woorde van Jesus in Johannes 7 oor strome lewende water wat uit die persoon sal vloei wat in Hom glo, gee Johannes die volgende interpretasie in vers 38: "Hiermee het Hy na die Gees verwys, want die mense wat tot geloof in Hom kom, sou die Gees ontvang. Die Gees was nog nie uitgestort nie, omdat Jesus toe nog nie verheerlik was nie." Hierdie kombinasie van water en gees mag bydra tot die verstaan van Johannes 3:5: "Jesus het geantwoord: 'Dit verseker Ek jou: As iemand nie uit water en Gees gebore word nie, kan hy nie in die koninkryk van God kom nie ...”

\section{NABETRAGTING EN VOORUITSKOUING}

Die rivier van die lewe in Esegiël 47:1-12 is 'n metaforiese voorstelling met sterk mitologiese ondertone. Spreke oor God is noodwendig metafories en mitologies. Die metafoor en die mite word bruikbaar gemaak binne 'n nuwe konteks. Onaanvaarbare aspekte van ou mites kry deur middel van metaforiese vertolking nuwe betekenis. Dit verwys na God se verlossingsdade en die geestelike herskepping van die volk (vgl Eichrodt 1970:585). God se selfkommunikasie vind volle uitdrukking in 'n innerlik vernude gemeenskap (vgl Eichrodt 1970:586).

Wanneer ons in 'n moderne konteks ons geloof wil bely, sal dit steeds in metaforiese en mitologiese taal moet wees. Daar sal ten minste rekening gehou moet word met die volgende Bybelse motiewe: God gee om vir die mens ten spyte van die inherente tekortkominge van die mens. Dit is God se wil dat daar 'n besondere verhouding tussen God en die mens moet bestaan. Die verhouding is nie altyd na wense nie. Die kwaliteit van die lewe van die mens word hierdeur geraak. Uit genade gryp God in in die lewe van mense en herstel hierdie verhouding. Dit het 'n heilsame uitwerking op die wese en lewe van die mens. 
Hierdie motiewe is reeds mitologies van aard. In die Bybel is dit op verskeie maniere uitgebeeld deur middel van verbeeldingryke, antieke mitologiese voorsteling. Die plek wat die Bybel in ons geloofsgemeenskap inneem, vereis dat ons in moderne spreke oor God ook moet rekening hou met Bybelse mitologiese voorstellings. Sommige van daardie voorstellings resoneer steeds effektief by die moderne gelowige as deel van sy of haar mitologiese leefwêreld. Ander voorstellings behoort meer metafories te funksioneer.

Analitiese, kliniese, eenduidige, ontologiese spreke oor God is nie moontlik nie. Wat belangrik is, is dat die spreke oor God moet resoneer in die diepste fasette van die menslike bewussyn. Hiervoor is die mite en die metafoor onontbeerlik. Die spreke oor God verkry dan 'n dinamika wat vernuwend inwerk op die lewens van mense. Ten spyte van 'n nederige oorsprong, word dit 'n stroom wat aangroei, herskep en lewe bring.

\section{Literatuurverwysings}

Ebeling, E 1953. Die akkadische Gebetsserie "Handerhebung". Berlyn: Walter de Gruyter \& Co.

Eichrodt, W 1970. Ezekiel. A commentary. London: SCM.

Gambush J 1992. Jerusalem in the book of Ezekiel: The city as Yahweh's wife. Atlanta: Scholars Press.

Halperin, D J 1993. Seeking Ezekiel. Text and psychology. University Park, PA: The Pennsylvania State University Press.

Jacobsen, T 1976. The treasures of darkness: A history of Mesopotamian Religion. New Haven: Yale University Press.

Keel, O \& Ühlinger, Ch. 1992. Göttinen, Götter und Gottessymbole: Neue Erkentnisse zur Religionsgeschichte Kanaans und Israels ägrund bislang unerschlossener ikonographischer Quellen. Freiburg: Herder.

Kraus, H-J 1978. Psalmen, I.Teilband: Psalmen 1-59. Neukirchen-Vluyn: Neukirchener Verlag. (BK XV/1).

Loader, J A 1990. A tale of two cities: Sodom and Gomorrah in the Old Testament, early Jewish and early Christian traditions. Kampen: JH Kok.

Neuss, W 1912. Das Buch Ezekiel in Theologie und Kunst bis zum Ende des XII. Jahrhunderts: Beiträge zur Geschichte des Mönchtums und des Benediktinerordens, no 112. Münster: Aschendorff. 
Schroer, S 1990. Psalm 65 - Zeugnis eines integrativen JHWH Glaubens? UF 22, 285-301.

Westermann, C 1976. Genesis. Neukirchen-Vluyn: Neukirchener Verlag.

Wildberger, H 1982. Jesaja, 3.Teilband: Jesaja 28-39. Das Buch, der Prophet und seine Botschaft. Neukirchen-Vluyn: Neukirchener Verlag. (BK X/3).

Zimmerli, W 1969. Ezekiel 25-48. Neukirchen-Vluyn: Neukirchener Verlag.

- 1983. Ezekiel 2. Philadelphia, PA: Fortres.

Zwickel, W 1995. Die Tempelquelle Esegiël 47: Eine traditionsgeschichtliche Untersuchung. Evang Theol 55(2), 140-154. 